\title{
CDISC SDTM Model Version 1.6
}

National Cancer Institute

\section{Source}

National Cancer Institute. CDISC SDTM Model Version 1.6. NCI Thesaurus. Code C161430.

The 1.6 version of the CDISC Study Data Tabulation Model (SDT M). 